\title{
AVALIAÇÃO DA FOTODEGRADAÇÃO DE POLIOLEFINAS ATRAVÉS DE EXPOSIÇÃO NATURAL E ARTIFICIAL
}

\author{
Guilhermino José Macêdo Fechine* \\ Instituto de Química, Universidade de São Paulo, Av. Prof. Lineu Prestes, 748, 05508-900 São Paulo - SP, Brasil \\ João Antônio Belmino dos Santos e Marcelo Silveira Rabello \\ Departamento de Engenharia de Materiais, Universidade Federal de Campina Grande, Av. Aprígio Veloso, 882, \\ 58109-970 Campina Grande - PB, Brasil
}

Recebido em 23/3/05; aceito em 13/9/05; publicado na web em 14/3/06

\begin{abstract}
THE EVALUATION OF POLYOLEFIN PHOTODEGRADATION WITH NATURAL AND ARTIFICIAL EXPOSURE. Samples of polypropylene (PP) and low-density polyethylene (LDPE) were submitted to ultraviolet radiation, in the natural environment and also in the laboratory. Chemical modifications were quantified by the carbonyl index (CI), mechanical properties and melt flow index. The degradation in the laboratory was comparatively faster than in the environment for both types of polymers. The accelerating factor was determined for the various properties investigated. This parameter, however, showed a large variation with the degradation criteria and the type of polymer. The existence of a "universal accelerating factor", therefore, was not observed in the current study.
\end{abstract}

Keywords: polypropylene; low-density polyethylene; photodegradation.

\section{INTRODUÇÃO}

Todos os polímeros orgânicos não estabilizados são degradados sob exposição à luz solar na presença de oxigênio. Entretanto, as taxas de degradação fotooxidativa dependem fortemente da natureza química do polímero, com a vida útil variando desde poucos meses para o polipropileno, até alguns anos para o politereftalato de etileno (PET), poli(metacrilato de metila) (PMMA) e o politetrafluoretileno ${ }^{1,2}$. Os problemas da fotodegradação têm aumentado com o crescente uso de polímeros em aplicações exteriores aliado à necessidade da redução de custos com aditivos fotoestabilizantes. Durante o processo degradativo ocorrem mudanças físicas e químicas no polímero que levam à descoloração, fissuramento, perda de brilho e queda de resistência mecânica. Tais fenômenos estão quase sempre associados a processos de cisão de cadeia e, em alguns casos, ocorrem também reticulações ${ }^{2}$.

A investigação da degradação foto-oxidativa de polímeros é um dos principais elementos que subsidiam o desenvolvimento do produto e sua expectativa de vida útil. Ao se expor o material às intempéries e avaliar os efeitos nas suas propriedades busca-se obter uma fotografia do que aconteceria durante a aplicação desse produto. Nesse tipo de investigação utilizam-se a exposição no ambiente natural e a exposição simulada, realizada em laboratório. Nas exposições em laboratório, as variáveis mais importantes são tipo de fonte geradora de radiação ultravioleta, intensidade de radiação, temperatura, umidade e ciclos térmicos ${ }^{3-8}$. A resposta do material à exposição depende, portanto, da intensidade dessas variáveis. É comum a intensificação desses fatores para aceleração da fotodegradação e, assim, se obter resultados mais rápidos. Outra maneira de se investigar a resistência fotoquímica dos polímeros é a exposição ambiental, onde os diversos constituintes do ambiente, como radiação ultravioleta, luz visível, temperatura, intempéries, umidade, etc, afetam a estrutura química do polímero provocando degradação. A intensidade desses elementos do ambiente

*e-mail: fechine@iq.usp.br natural varia significativamente com o local de exposição, a época do ano e o período do dia, de tal modo que as exposições naturais se tornam únicas e, muitas vezes, irreprodutíveis.

Embora os procedimentos de exposição em laboratório sejam amplamente aplicados em estudos de degradação de polímeros, existem, relativamente, poucos trabalhos envolvendo exposições naturais $^{9-16}$. Isto, em parte, é devido à difícil reprodutibilidade desse tipo de exposição e também por ser um procedimento de longa duração. Por outro lado, é a única que expõe as amostras em situação real de uso, ao contrário das exposições em laboratório, que tentam simular de alguma forma um processo ambiental. A variabilidade dos elementos na natureza é o aspecto que mais dificulta a simulação da fotodegradação em laboratório, onde geralmente se utilizam condições padronizadas e controladas. Algumas tentativas de encontrar uma equivalência entre exposições naturais e artificiais foram realizadas e relatadas na literatura ${ }^{17-29}$, mas os resultados obtidos parecem ser insuficientes para se propor correlações mais abrangentes entre o ambiente e os sistemas de exposição. $\mathrm{O}$ tema ainda é muito controverso, carecendo de um maior número de estudos.

Neste trabalho pretende-se avaliar possíveis correlações entre as exposições natural e artificial do polietileno de baixa densidade e do polipropileno, observando-se também o grau multiplicador da exposição artificial em relação à natural. Estes dois tipos de polímeros apresentam mecanismos de degradação fotoquímica diferentes, com predominância de reações de cisão de cadeia no polipropileno e reações de reticulação, no polietileno de baixa densidade. Amostras submetidas a diversos períodos de exposição foram caracterizadas quanto a variações na massa molar, modificações químicas e propriedades mecânicas, as quais foram observadas por meio de medidas de índice de fluidez, espectroscopia, no infravermelho e ensaios de tração, respectivamente.

\section{PARTE EXPERIMENTAL}

Utilizou-se o polietileno de baixa densidade (PEBD) do tipo G-803, cedido pela Politeno, e o polipropileno KM 6100 fabricado 
pela Polibrasil. Trata-se de grades comerciais utilizadas no processamento por injeção, não contendo aditivos fotoestabilizantes. Por se tratar de tipos comerciais, poucas informações foram disponibilizadas com relação às estruturas moleculares desses polímeros.

A moldagem dos corpos-de-prova em forma de chapas planas com dimensões $14 \mathrm{~cm} \mathrm{x} 14 \mathrm{~cm}$ x $0,45 \mathrm{~mm}$ foi feita em uma prensa hidráulica equipada com sistema de aquecimento e com capacidade máxima de 15 t. A exposição natural dos corpos-de-prova foi feita em uma estante fabricada de acordo com a norma ASTM D 1435-85 [3]. A estante está localizada em Campina Grande - PB (altitude de 547,56 m, com latitude e longitude de $07^{\circ} 13 \mathrm{~S}$ e $35^{\circ} 53 \mathrm{~W}$, respectivamente). Durante o período de exposição avaliou-se o nível de radiação global (é a energia radiante por unidade de tempo e de área incidente em uma superfície, expressa em $\mathrm{W} / \mathrm{m}^{2}$, dada pela soma de suas componentes direta e difusa) incidente na cidade e os demais parâmetros ambientais (temperaturas máxima e mínima, umidade e precipitação), utilizando-se dados gentilmente fornecidos pela EMBRAPA. Detalhamento desses dados podem ser encontrados em publicação anterior ${ }^{30}$. O local possui alta umidade e, no ano de exposição, a precipitação pluviométrica foi relativamente baixa, restringindo-se a apenas dois meses chuvosos. A exposição artificial foi feita em uma câmara de intemperismo acelerado tipo C-UV fabricado pela Comexim. A fonte de radiação foi lâmpadas fluorescentes Philips de $40 \mathrm{~W}$, com emissão de ultravioleta entre 280 e $350 \mathrm{~nm}$, com boa equivalência com a radiação solar. Nas condições utilizadas a dose diária de radiação ultravioleta é de cerca de $50 \mathrm{Wh} / \mathrm{m}^{2}$, enquanto que no ambiente natural a dose diária variou de 18,3 na estação de chuvas a $26,3 \mathrm{Wh} / \mathrm{m}^{2}$ na estação seca. $\mathrm{O}$ equipamento de intemperismo acelerado possui controle de temperatura, temporizadores e atmosfera úmida. $\mathrm{O}$ ciclo utilizado foi 4 h de lâmpadas ligadas a uma temperatura de $60^{\circ} \mathrm{C}$, seguida de $4 \mathrm{~h}$ de lâmpadas desligadas a uma temperatura de $50{ }^{\circ} \mathrm{C}$, sob condensação, levando a uma combinação de degradação fotoquímica e térmica. O tempo de exposição relatado refere-se apenas ao tempo de lâmpadas ligadas (horas de exposição à luz ultravioleta). Para poder se fazer uma comparação entre os tempos de exposição das amostras expostas natural e artificialmente, padronizou-se que $12 \mathrm{~h}$ de exposição artificial equivaleria a um dia de exposição natural.

Os ensaios mecânicos foram conduzidos em uma Máquina Universal de Ensaios Testometric Micro 350, com velocidade de carregamento de $40 \mathrm{~mm} / \mathrm{min}$, e corpos-de-prova cortados antes da exposição à radiação UV com dimensões de $10 \times 2 \times 0,45 \mathrm{~cm}$, e comprimento útil de $6 \mathrm{~cm}$. Através deste ensaio mecânico foram obtidas as propriedades de resistência à tração (RT) e elongação máxima $\left(\varepsilon_{\text {máx }}\right)$. As análises de MFI foram feitas em um Plastômetro DSM, modelo MI3. As análises de Infravermelho por FTIR foram feitas em um Espectofotômetro BOMEM MB, em uma faixa de 400 a $4000 \mathrm{~cm}^{-1}$, com resolução de $2 \mathrm{~cm}^{-1}$ e os espectros foram obtidos através do acúmulo de 20 varreduras. A partir dos espectros determinou-se os índices de carbonila (IC) dos dois tipos de polímeros como a razão entre a absorbância da carbonila (em $1720 \mathrm{~cm}^{-1}$ ) e a absorbância de referência. Este procedimento visa eliminar a influência das diferentes espessuras dos filmes, sendo utilizados como picos de referência os centrados em 2720 e $2030 \mathrm{~cm}^{-1}$ para polipropileno e polietileno, respectivamente ${ }^{31}$. Nas amostras de polietileno determinou-se o teor de gel através da fração retida após dissolução em xileno a $138{ }^{\circ} \mathrm{C}$, seguindo procedimentos descritos na literatura ${ }^{32}$.

\section{RESULTADOS E DISCUSSÃO}

Sabe-se que tanto o polietileno (PE) como o polipropileno (PP) não absorvem radiação UV em valores superiores a $250 \mathrm{~nm}$. Como a radiação solar que alcança a superfície terrestre possui comprimentos de onda superiores a $290 \mathrm{~nm}$, a iniciação da fotodegradação desses polímeros é atribuída à absorção de radiação UV por impurezas cromóforas, como resíduos de catalisador e hidroperóxidos gerados durante o processamento. A absorção da radiação UV por esses cromóforos inicia uma série de reações químicas fotooxidativas, que geram grupos químicos como carbonila e hidroperóxidos e provocam reações de cisão de cadeia e/ou de reticulação ${ }^{1,5,33}$.

\section{Medidas de índice de fluidez e de infravermelho}

A Figura 1 mostra o efeito do tempo e tipo de exposição no índice de fluidez do polipropileno. Devido ao alto número de cisão de cadeias, o valor do MFI das amostras expostas natural e artificialmente aumentou bastante, chegando a valores que não puderam ser medidos, uma vez que o fluxo da massa polimérica pela matriz era muito rápido e descontínuo. De acordo com vários autores ${ }^{1,34,35}$, este tipo de comportamento é conseqüência do mecanismo de degradação do PP, que envolve reações de quebra de cadeias, que ocorrem através da cisão $\beta$ de radicais alcoxi (PPO•) gerados pela auto-oxidação do PP (reação 3 do Esquema 1) ou pela foto-clivagem de hidroperóxidos (reação 5). Como subproduto dessas reações temse a formação de grupos carbonila, que é o principal grupo químico característico da degradação oxidativa do PP.

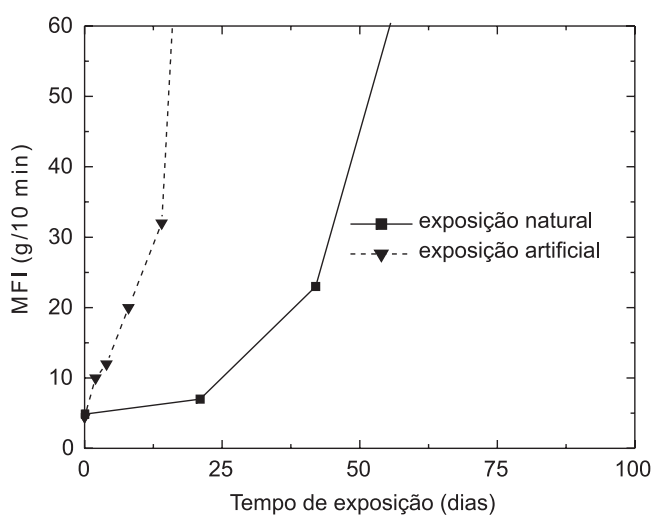

Figura 1. Efeito do tempo de exposição no MFI do PP

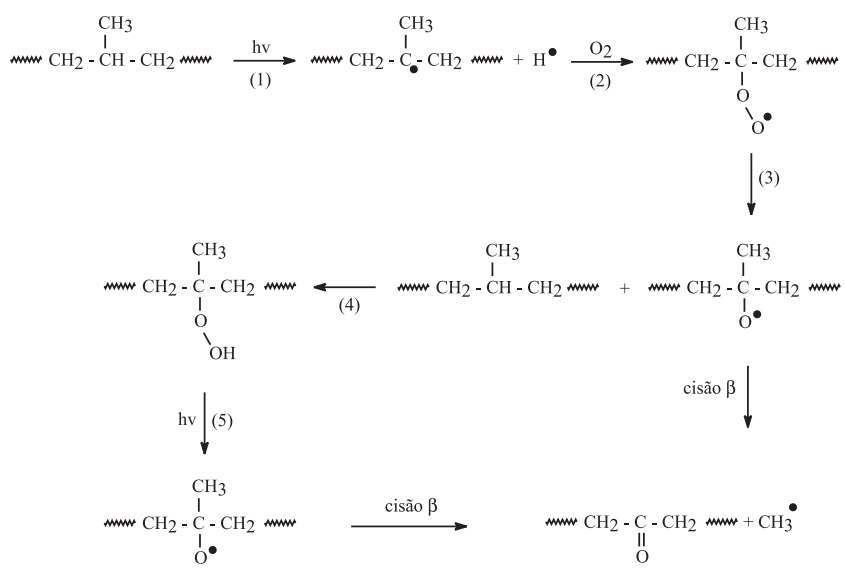

Grupos carbonila

Esquema 1. Reações que levam à cisão de cadeia e à formação de grupos carbonila no PP 
A Figura 2 mostra que a evolução da concentração dos grupos carbonila durante a fotodegradação do PP é bem mais rápida para a exposição artificial, sendo consistente com dados de MFI. Observase também na Figura 2 que as amostras expostas ao ambiente natural apresentam um tempo de indução de cerca de 40 dias, a partir do qual o IC começa a apresentar aumentos mais significativos. Nas amostras expostas artificialmente, houve um aumento progressivo na extensão da degradação, em termos de IC, sem que ficasse aparente algum tempo de indução. O tempo de indução para a observação da degradação de polímeros está relacionado com diversos fatores, incluindo consumo de aditivos estabilizantes, difusão de oxigênio para o produto, geração de hidroperóxidos e outras espécies reativas e condições de exposição como temperatura, intensidade de radiação ultravioleta, etc ${ }^{36}$. Um comparativo sobre o fator de aceleração entre as exposições natural e artificial será apresentado posteriormente para os dois tipos de polímeros estudados.

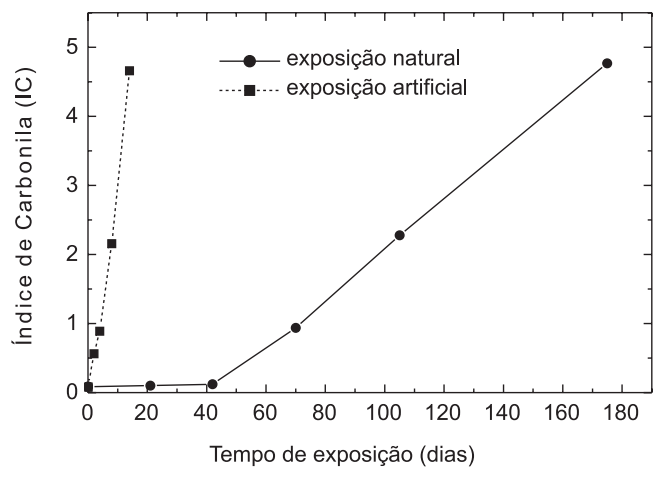

Figura 2. Índice de carbonila das amostras de PP expostas ao intemperismo natural e artificial

Nas duas avaliações da extensão da degradação química realizadas, por MFI e por FTIR, observou-se um nível maior de degradação nas amostras expostas em laboratório. Essa diferença está relacionada com a maior intensidade de emissão da radiação UV das lâmpadas fluorescentes em comparação com o ambiente natural e também com a maior temperatura de exposição. Como as reações de cisão de cadeia estão diretamente relacionadas à absorção da radiação ultravioleta (Esquema 1), era de se esperar uma maior extensão de degradação química nas amostras expostas em laboratório.

Ao contrário do PP, em que as reações de cisão de cadeia são predominantes sobre as reações de formação de reticulações, o PEBD apresenta em alguns níveis de degradação uma eficiência nas reações de reticulação bem superior às de cisão de cadeia, principalmente na ausência de oxigênio (reação 2, Esquema 2), onde os radicais alquila secundários são suficientemente estáveis para que ocorra uma recombinação. Outro fato importante é que da mesma maneira que o PP, a cisão de cadeia do PEBD através das reações de fotólise dos hidroperóxidos também gera grupos carbonila (reação 5, Esquema 2).

A Figura 3 apresenta os valores de MFI para o PEBD exposto às duas diferentes condições. Nota-se uma variação do MFI semelhante para os dois casos, mas em tempos variados, sugerindo uma mudança significativa na taxa de reação. $O$ índice de fluidez diminui consideravelmente nos tempos iniciais de exposição em laboratório para valores próximos de zero. Neste estágio, observa-se uma retenção do "melt" no equipamento de medição, indicando a ocorrência de reticulação como provável causa da queda acentuada na fluidez. Medidas de teor de gel foram realizadas em algumas amostras, indicando um aumento progressivo na fração retida, i.e.,

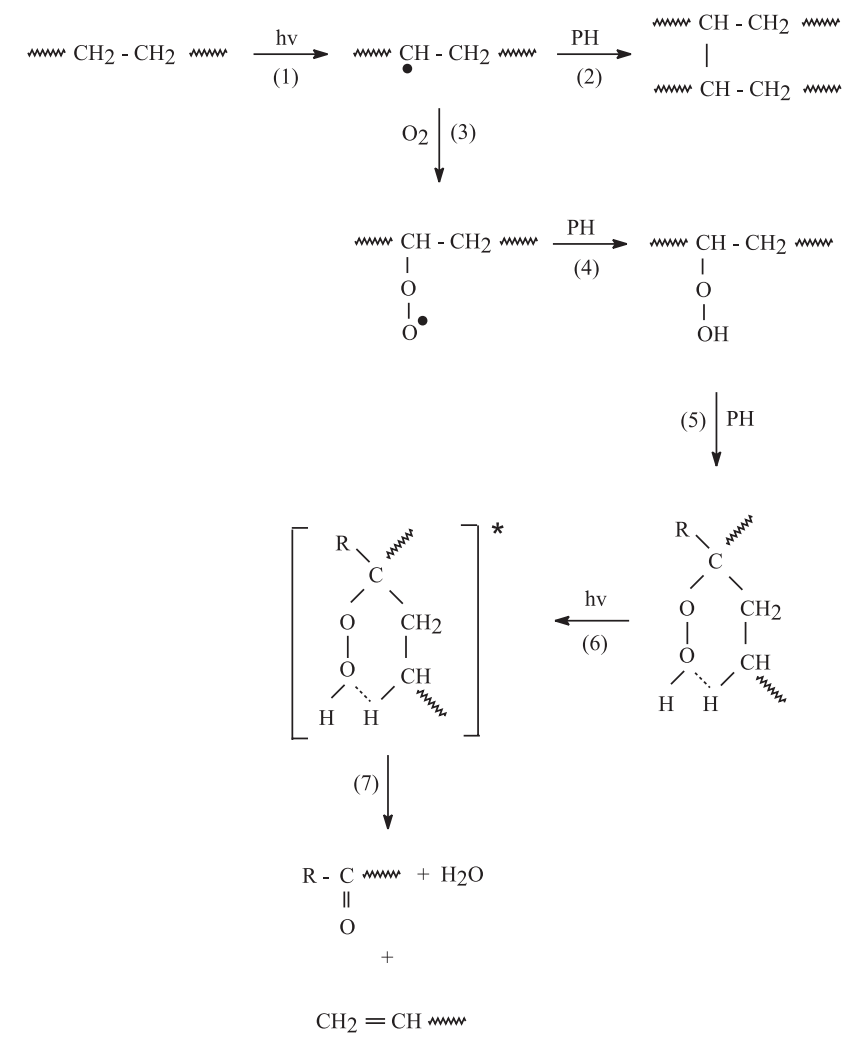

Esquema 2. Reações de radicais alquila durante fotodegradação do PEBD

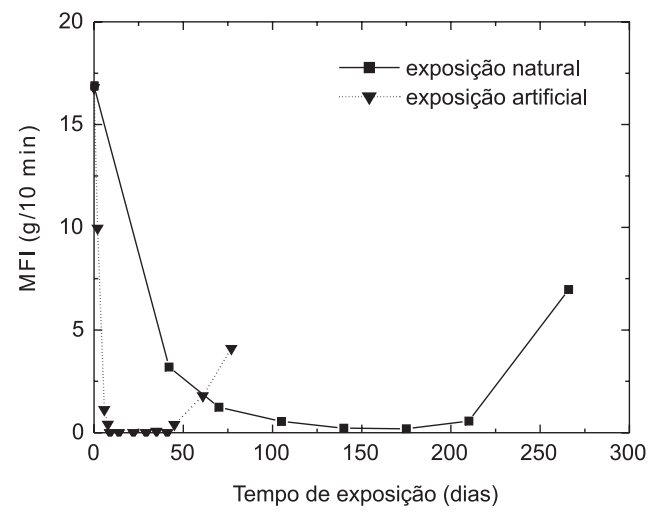

Figura 3. Efeito do tempo de exposição no MFI do PEBD

no percentual reticulado existente. Esses resultados estão mostrados na Figura 4. Note que a fração retida aumenta continuamente até apresentar um decréscimo que coincide com o aumento no MFI observado em tempos mais prolongados. Na exposição natural a redução pronunciada no índice de fluidez do PEBD também foi observada, mas em tempos mais longos de degradação. Depois de determinados tempos de exposição, o MFI apresenta tendência de aumento, observado para dois tipos de exposição. Esse fator foi discutido anteriormente ${ }^{37}$ e pode estar relacionado com a difusão de oxigênio atmosférico para o interior dos corpos de prova, com consequiente formação de grupos peróxido reativos que levam à cisão de cadeia (Esquema 2).

A diferença na taxa das reações de foto-oxidação do PEBD exposto natural e artificialmente está relacionada com a difusão do oxigênio para o interior das amostras e com a intensidade de radiação ${ }^{38,39}$. $\mathrm{Na}$ exposição artificial a intensidade da radiação ultravioleta é muito alta e a taxa de reação torna-se muito rápida, 


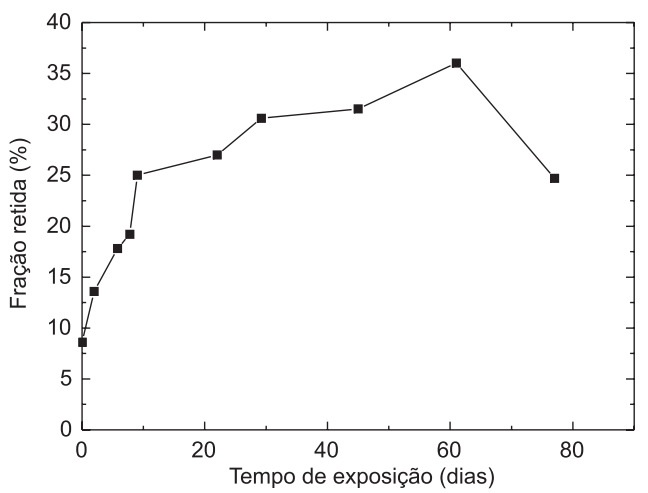

Figura 4. Fração retida das amostras de PEBD expostas em laboratório

com o oxigênio sendo mais rapidamente consumido nas reações em camadas superficiais da amostra. Esse rápido consumo de oxigênio na superfície torna o interior com escassez de oxigênio e, assim, a ação da luz ultravioleta no interior da amostra leva a reações de reticulação como as mostradas no Esquema 2 (reação 2). $\mathrm{Na}$ exposição natural a intensidade de radiação é mais baixa e talvez o oxigênio possa difundir parcialmente para o interior da amostra, sem reagir na superfície. Assim, o interior apresentaria uma tendência um pouco menor de reticulação. Isto ocorre em estágios iniciais de degradação, enquanto que em tempos de exposição mais prolongados o oxigênio consegue atingir o interior das amostras (especialmente nas regiões amorfas), e assim as reações de cisão de cadeia voltam a dominar o processo fotodegradativo. Os resultados relatados por Torikai e colaboradores $^{40}$ reforçam esse argumento, onde eles demonstram que regiões cristalinas de PEBD são mais susceptíveis às reações de reticulação do que à cisão de cadeias, devido à ausência de oxigênio nestas regiões.

Como as reações que geram reticulações no PEBD não levam à formação de grupos carbonila (Esquema 2), os resultados de índice de carbonila do PEBD apresentados na Figura 5 mostram valores numéricos bem inferiores aos do PP.

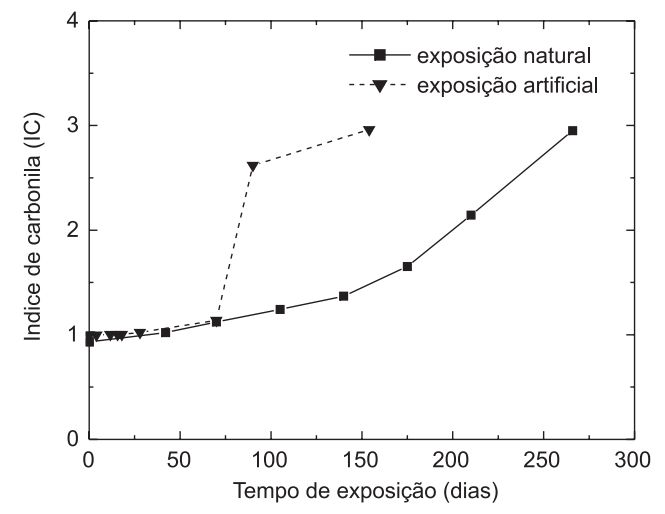

Figura 5. Índice de carbonila das amostras de PEBD expostas à radiação UV

\section{Propriedades mecânicas}

A Figura 6 mostra que a resistência à tração do PP começa a diminuir fortemente a partir de 42 dias de exposição natural, enquanto que na exposição artificial a redução nessa propriedade é observada em apenas 4 dias, indicando uma grande aceleração na deterioração mecânica deste polímero. Após cerca de 14 dias de exposição artificial as peças apresentaram intensa fragilidade, com fragmentação ao toque. Este estado foi atingido na exposição natural após $~ 175$ dias. De acordo com esse critério, a exposição em laboratório representa um fator de aceleração de $12,5 \mathrm{x}$ em relação à exposição ao ambiente natural. Um critério comumente adotado na literatura para avaliar a aceleração é o tempo necessário para uma redução de $50 \%$ na resistência mecânica ${ }^{41}$. Com os dados mostrados na Figura 6 tem-se, com esse critério, um fator de aceleração de, aproximadamente, $8 x$.

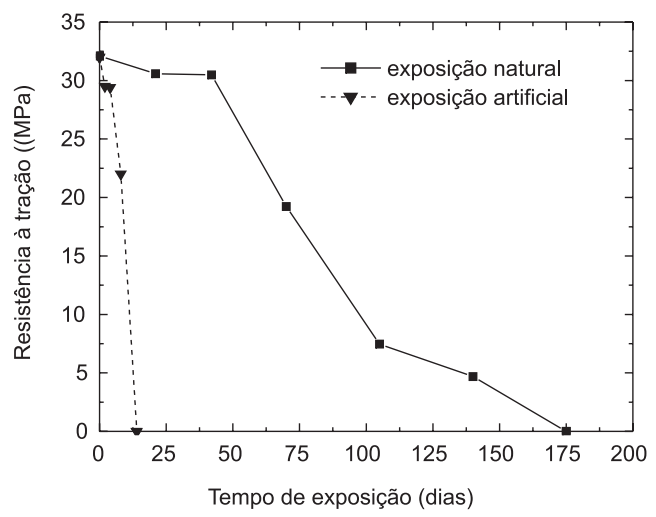

Figura 6. Efeito do tempo de exposição na resistência à tração do PP

Os efeitos da radiação ultravioleta no comportamento mecânico do PP têm sido relatados por vários autores ${ }^{1,34,42,43}$. Observa-se, em geral, uma redução drástica nas propriedades mecânicas, fato atribuído às reações oxidativas que levam à cisão de cadeias principalmente na região das moléculas que participam de mais de uma lamela cristalina (as chamadas moléculas atadoras), que, juntamente com a formação de fissuras superficiais, provoca grande deteriorização na resistência. As reações de cisão de cadeia reduzem a massa molar do polímero, como pode ser observado indiretamente pelo aumento significativo do índice de fluidez e geração de grupos carbonila, Figuras 1 e 2, respectivamente. Assim como a resistência à tração, a elongação máxima também diminui drasticamente com a exposição (Figura 7) e, novamente, os efeitos são mais significativos em amostras expostas em laboratório.

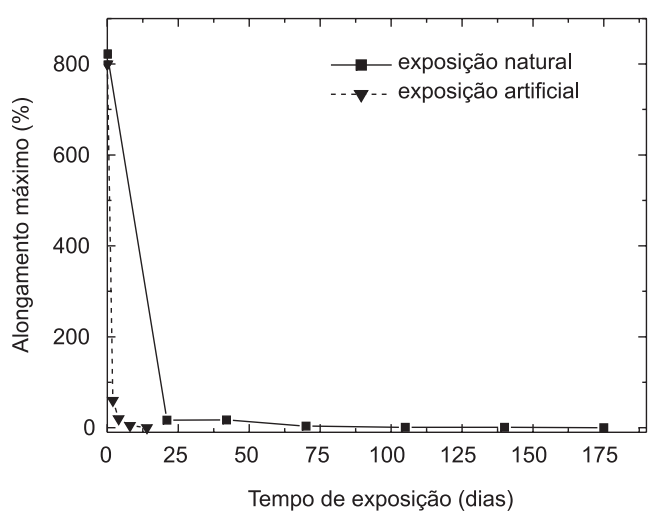

Figura 7. Efeito do tempo da exposição na elongação máxima do PP

As curvas tensão-deformação do PP virgem e fotodegradado estão mostradas na Figura 8. Observa-se que o polímero não-exposto possui um comportamento altamente dúctil, com estricção e escoamento extensivo do corpo de prova, e ocorrência da ruptura após uma grande deformação. Ao se comparar com o material exposto por 70 dias no ambiente natural, nota-se a ocorrência de fra- 


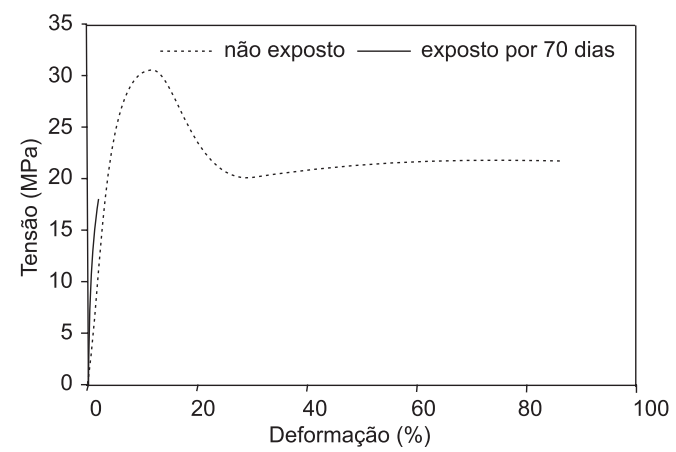

Figura 8. Curvas tensão-deformação do PP não-degradado e degradado no ambiente natural

tura frágil com pouca ou nenhuma deformação permanente e que a ruptura ocorreu em tensões consideravelmente menores.

No caso do PEBD, os valores de resistência à tração (Figura 9) após diferentes tempos de exposição natural não mostraram nenhuma modificação sistemática, enquanto que nas amostras expostas artificialmente ocorreu inicialmente uma pequena diminuição, e em seguida montaram-se algumas oscilações sem tendência definitiva. Este comportamento pode estar relacionado com as reações de cisão e reticulação que ocorrem simultaneamente durante o processo fotodegradativo do PEBD. Dependo do tipo (cisão ou reticulação), da localização (regiões amorfa, cristalina e de moléculas atadoras) e da quantidade de cada uma dessas reações, a resistência tênsil do material poderá ou não ser afetada. Como conseqüência dessas variantes pode-se obter uma resposta que representa uma combinação de efeitos dessas reações. A elongação máxima, por ser uma propriedade mais diretamente influenciada pelas variações em massa molar, apresentou maior sensibilidade aos efeitos foto-oxidativos (Figura 10). Os dados relatados na Figura 9 mostram que em ambos os tipos de exposição ocorreu um decréscimo nos valores de elongação máxima com o aumento do tempo de exposição. A única diferença entre os tipos de exposição, como era de se esperar, é a velocidade de decréscimo desse parâmetro.

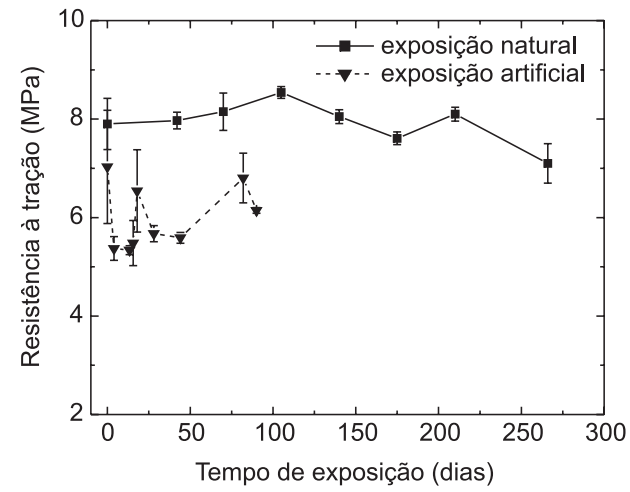

Figura 9. Efeito do tempo de exposição na resistência à tração do PEBD

As curvas tensão-deformação do PEBD virgem e fotodegradado estão apresentadas na Figura 11. Nota-se uma grande semelhança de comportamento até o início do escoamento e, após esta fase, o material exposto apresentou fratura em baixa deformação, mantendo-se praticamente a mesma tensão máxima (RT). Uma explicação para este fato é que as reticulações geradas durante o processo degradativo levariam a um fortalecimento da coesão entre os cristais, evitando que ocorresse maior deformação (escoamento). A queda acentuada

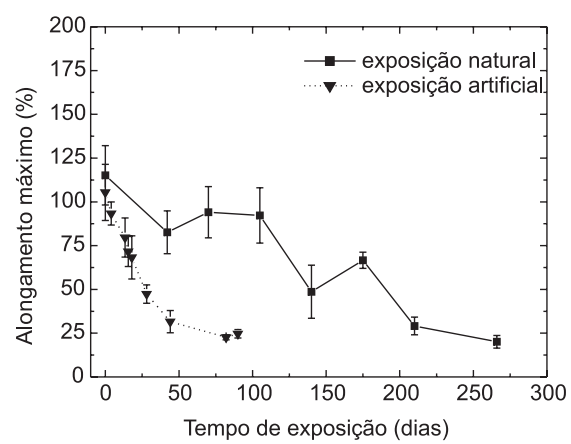

Figura 10. Efeito do tempo de exposição na elongação máxima do PEBD

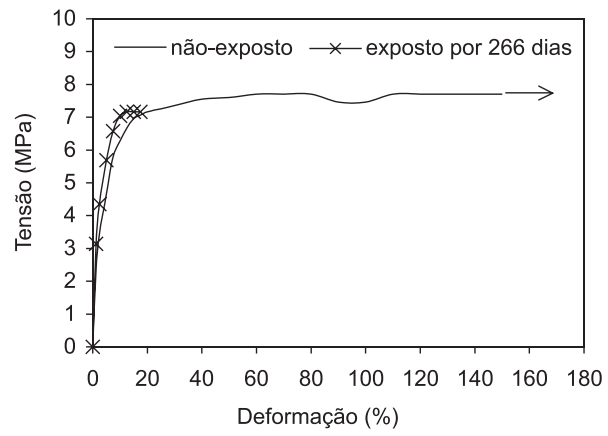

Figura 11. Curvas tensão-deformação do PEBD virgem e degradado no ambiente natural

na resistência à tração do PEBD exposto em laboratório por tempos mais prolongados (Figura 9) pode estar associada com a intensa quebra de cadeias que ocorre em períodos posteriores (como observado pelos dados de MFI mostrados na Figura 3).

\section{Análise do fator de aceleração}

Com os dados apresentados neste estudo observou-se que a degradação em laboratório foi nitidamente mais acentuada que a degradação ambiental para os dois tipos de polímeros investigados e em todas as propriedades analisadas. A questão que sempre surge ao se realizar exposições em laboratório é: em quanto tempo os resultados mostrados serão observados em situações práticas? Essa questão implica em se determinar se existe correlação entre os dois tipos de exposição e qual o fator de aceleração. Evidentemente, as características do ambiente natural variam muito de local para local e de período a período e, portanto, a questão deverá ser tratada apenas no contexto deste estudo, ou seja, para o local utilizado nas exposições naturais. Como citado anteriormente, diversos trabalhos realizaram uma comparação entre os processos de exposição natural e artificial, porém, poucos quantificaram os fatores de aceleração. Nos artigos de Tidjani e colaboradores ${ }^{17,25}$, relaciona-se o fator de aceleração com o valor da absorbância do grupo carbonila gerado durante o processo fotodegradativodo PP e do PEBD. O uso do "fator de aceleração" para quantificar a correlação entre os dois tipos de exposição baseado em apenas uma propriedade confere uma visão parcial que pode ser útil em algumas situações e para alguns tipos de polímeros. Essa visão simplificatória do fator de aceleração muitas vezes é tomada como verdade absoluta, podendo levar a super ou sub-estimativas no projeto de componentes utilizados em aplicações externas.

Em contraposição, neste trabalho foram feitos cálculo de diversos "fatores de aceleração", cada um relacionado com um 
parâmetro analisado nos dois tipos de polímero. Os resultados estão mostrados nas Tabelas 1 e 2 . O cálculo dos fatores de aceleração é obtido pela razão entre o tempo (em dias) para se atingir uma determinada propriedade em exposição natural e o tempo para se alcançar a mesma propriedade em exposição laboratorial. Os resultados apresentados mostram uma variação de valores de fator de aceleração, de 3,5 a 13,1, dependendo do material e do critério adotado. Com esses resultados pode-se afirmar que para os casos aqui apresentados, pode-se considerar que não existe um "fator de aceleração geral", válido para o equipamento e condições ambientais utilizados. A tentativa de se adotar um valor de fator de aceleração deverá ser cuidadosamente analisada, ou seja, deverá se indicar qual parâmetro foi usado para determinado polímero. Um exemplo claro para isso seria a escolha do valor de IC igual a 2 como parâmetro de cálculo de fator de aceleração. Não se poderia comparar esse parâmetro, que avalia modificações na estrutura química, com valores de fator de aceleração baseados em redução em $50 \%$ da resistência tênsil, já que existe uma diferença na sensibilidade entre mudança da estrutura química e no comportamento mecânico de um polímero

A resposta de cada tipo de propriedade aos efeitos ambientais e de laboratório parece ser variada, impossibilitando a existência de uma correlação definitiva entre os dois procedimentos. $\mathrm{O}$ fato de não existir uma correlação direta e definitiva entre as duas exposições não invalida os estudos desenvolvidos em laboratório. Os mecanismos são os mesmos que ocorrem nas exposições ambientais e, por serem mais rápidos e reprodutíveis, possibilitam investigações importantes como o desenvolvimento de formulações com estabilizantes, a influência de tipos de aditivos e os fatores que controlam a fotodegradação. Como a magnitude de mudanças é, de certa forma, imprevisível em termos de exposição natural, as exposições ambientais continuam sendo essenciais quando são necessárias determinações mais precisas sobre o comportamento dos produtos poliméricos.

Tabela 1. Fatores de aceleração para polipropileno, com base no tempo (em dias) para se atingir um determinado critério

\begin{tabular}{lccc}
\hline Critério & $\begin{array}{c}\text { Exposição } \\
\text { natural }\end{array}$ & $\begin{array}{c}\text { Exposição } \\
\text { artificial }\end{array}$ & $\begin{array}{c}\text { Fator de } \\
\text { aceleração }\end{array}$ \\
\hline MFI de 30 g/10 min & $\sim 45,0$ & $\sim 13,0$ & $\sim 3,5$ \\
IC de 2,0 & $\sim 100,0$ & $\sim 8,0$ & $\sim 12,5$ \\
RT (50\% de redução) & $\sim 80,0$ & $\sim 10,0$ & $\sim 8,0$ \\
Alongamento & $\sim 11,0$ & $\sim 2,0$ & $\sim 5,5$ \\
(50\% de redução) & & & \\
RT (valor zero) & $\sim 175,0$ & $\sim 14,0$ & $\sim 12,5$ \\
\hline
\end{tabular}

Tabela 2. Fatores de aceleração para polietileno, com base no tempo (em dias) para se atingir um determinado critério

\begin{tabular}{lccc}
\hline Critério & $\begin{array}{c}\text { Exposição } \\
\text { natural }\end{array}$ & $\begin{array}{c}\text { Exposição } \\
\text { artificial }\end{array}$ & $\begin{array}{c}\text { Fator de } \\
\text { aceleração }\end{array}$ \\
\hline MFI (valor zero) & $\sim 105,0$ & $\sim 8$ & $\sim 13,1$ \\
IC de 2,0 & $\sim 200$ & $\sim 40$ & $\sim 5$ \\
Alongamento & $\sim 135,0$ & $\sim 26,0$ & $\sim 5,2$ \\
(50\% de redução) & & & \\
\hline
\end{tabular}

\section{CONCLUSÕES}

Os processos degradativos no polipropileno e no polietileno de baixa densidade são diferentes, com predomínio de reações de ci- são de cadeia no PP, enquanto que no PEBD ocorrem também reticulações. Em ambos a taxa de reação fotodegradativa foi acelerada nas exposições em laboratório, com a ocorrência das transformações físicas e químicas em tempos menores. A determinação do fator de aceleração da degradação em laboratório em relação à degradação ambiental mostrou que este parâmetro varia consideravelmente conforme o tipo de polímero e o critério utilizado na sua determinação. Dessa forma, a existência de um fator de aceleração universal, válido para todos os polímeros e independentemente do critério adotado, não foi observada no presente estudo e acreditase ser tecnicamente impossível obtê-lo. Nos casos em que se utilizar o conceito de fator de aceleração, este deve ser empregado com limitações pois, como mostrado neste estudo, depende do polímero, da propriedade avaliada e do local de exposição.

\section{AGRADECIMENTOS}

À Polibrasil e Polialden pela doação dos polímeros e ao PADCT pelo apoio financeiro. G. J. M. Fechine e J. A. B. Santos foram apoiados pela CAPES.

\section{REFERÊNCIAS}

1. Carlsson, D. J.; Wiles, D. M.; J. Macromol. Sci. 1976, C14, 65.

2. Allen, N. S.; Engineering Plastics 1995, 8, 247.

3. Gordienko, V. P.; Dmitriev, Y. A.; Polym. Degrad. Stab. 1996, 53, 79.

4. Sánchez-Solís, A.; Estrada, M. R.; Polym. Degrad. Stab. 1996, 52, 305.

5. Girois, S.; Audouin, L.; Verdu, J.; Delprat, P.; Marot, G.; Polym. Degrad. Stab. 1996, 51, 125.

6. Fechine, G. J. M.; Rabello, M. S.; Souto-Maior, R. M.; Polym. Degrad. Stab. 2002, 75, 153.

7. Fechine, G. J. M.; Rabello, M. S.; Souto-Maior, R. M.; J. Mater. Sci. 2002, 37,4979 .

8. Guedri, L.; Bem Amor, S.; Gardette, J. L.; Jacquet, M.; Rivaton, A.; Polym. Degrad. Stab. 2005, 88, 199.

9. Gallo, R.; Severini, F.; Ipsale, S.; Del Fanti, N.; Polym. Degrad. Stab. 1997, $55,199$.

10. O'Donnell, B.; Qayyum, M. M.; Tong, L.; White, J. R.; Plast., Rubber Compos. 1994, 21, 297.

11. Qayyum, M. M.; White, J. R.; Polymer 1987, 28, 469.

12. Iwu, C. F.; Egbuhuzor, O. M.; Proceedings of Annual Technical Conference, Society of Plastics Engineers, Nigeria, 2004.

13. Kaczmarek, H.; Swiatek, M.; Kaminska, A.; Polym. Degrad. Stab. 2004, 83,35 .

14. Kaci, M.; Touati, N.; Setnescu, R.; Tanta, J.; Int. J. Polym. Anal. Charact. 2004, 9, 275.

15. Valadez-Gonzales, A.; Veleva, L.; Polym. Degrad. Stab. 2004, 83, 139.

16. Kerboua, N.; Benachour, D.; Kaci, M.; Sadoun, T.; Rouba, N.; Ann. Chim. 2004, 29, 113.

17. Tidjani, A.; J. Appl. Polym. Sci. 1997, 64, 2497.

18. Matsumoto, S.; Ohshima, H.; Hasuda, Y.; J. Polym. Sci., Part A: Polym. Chem. 1984, 22, 869.

19. Kaci, M.; Hebal, G.; Touati, N.; Rabouhi, A.; Zaidi, L.; Djidjelli, H.; Macromol. Mater. Eng. 2004, 289, 681.

20. LaCount, B. J.; Castro, J. M.; Ignatz-Hoover, F.; Polym. Degrad. Stab. 2002, $75,213$.

21. Gijsman, P.; Hennekens, J.; Janssen, K.; Polym. Degrad. Stab. 1994, 46, 63.

22. Hamid, S. H.; Amin, M. B.; J. Appl. Polym. Sci. 1995, 55, 1385.

23. Meekum, U.; Kenharaj, R.; Proceedings of the International Conference on Enviromental Science and Technology, Greece, 2003.

24. Abu-Sharkh, B. F.; Hamid, H.; Polym. Degrad. Stab. 2004, 85, 967.

25. Tidjani, A.; Arnoud, R.; Silva, A.; J. Appl. Polym. Sci. 1993, 47, 211.

26. Tidjani, A.; Polym. Degrad. Stab. 1993, 39, 285.

27. Gasa, J. V.; Liu, Z.; Shaw, M. T.; Polym. Degrad. Stab. 2005, 87, 77.

28. Real, L. P.; Gardette, J. L.; Rocha, A. P.; Polym. Degrad. Stab. 2005, 88, 357.

29. Bracci, S.; Melo, M. J.; Polym. Degrad. Stab. 2003, 80, 533.

30. Rabello, M. S.; Tocchetto, R. S.; Barros, L. A.; D'Almeida, J. R. M.; White, J. R.; Plast., Rubber Compos. 2001, 30, 132.

31. Fechine, G. J. M.; Dissertação de Mestrado, Universidade Federal da Paraíba, Brasil, 1998. 
32. Valadez-Gonzales, A.; Cervantes, J. M.; Valeva, L.; Polym. Degrad. Stab. 1999, 63, 253.

33. Carlsson, D. J.; Grattan, D. W.; Suprunchuk, T.; Wiles, D. M.; J. Appl. Polym. Sci. 1978, 22, 2217.

34. Rabello, M. S.; White, J. R.; Polym. Degrad. Stab. 1997, 56, 55.

35. Tang, L.; Wu, Q.; Qu, B.; J. Appl. Polym. Sci. 2005, 95, 270.

36. Feller, R. L.; Accelerated Aging - Photochemical and Thermal Aspects, Library of Congress Cataloging -in- Publication Data, 1994.

37. Santos, J. A.B.; Dissertação de Mestrado, Universidade Federal da Paraíba, Brasil, 2000.
38. Tidjani, A.; Watanabe, Y.; Polym. Degrad. Stab. 1995, 49, 299.

39. Tidjani, A.; Polym. Degrad. Stab. 2000, 68, 465.

40. Torikai, A.; Shirakawa, H.; Nagaya, S.; Fueki, K.; J. Appl. Polym. Sci. 1990, 40, 1637.

41. Jiangquing, P.; Hongmei, X.; Juying, Q.; Jinfen, C.; Zhenmin, M.; Polym. Degrad. Stab. 1991, 33, 67

42. Rabello, M. S.; White, J. R.; J. Appl. Polym. Sci. 1997, 64, 2505.

43. Shyichuk, A. V.; Turton, T. J.; White, J. R.; Syrotynska, I. D.; Polym. Degrad. Stab. 2004, 86, 377. 